\title{
CAN HUMAN TOXOPLASMOSIS BE WITHIN THE DIFFERENTIAL DIAGNOSIS OF FEVER OF UNKNOWN ORIGIN: A CROSS-SECTIONAL STUDY
}

\section{By}

\author{
AHMED M. ARNOUS ${ }^{1}$, NAHLA E. ELGAMMAL ${ }^{2 *}$, NAHED E. MOSTAFA ${ }^{3}$, \\ EMAN M. FAWZY ${ }^{3}$ and MARWA A. SALAMA ${ }^{3}$ \\ Port-Said Fever Hospital ${ }^{1}$, Port-Said Governorate, Department of Tropical Medicine ${ }^{2}$, \\ and Department of Medical Parasitology ${ }^{3}$, Faculty of Medicine, Zagazig University, \\ Zagazig, Egypt (*Correspondence: nahoodaah58@gmail.com) Mob: 01100720092; \\ ORCID ID: 0000-0002-3853-5743
}

\begin{abstract}
More than 200 diseases can be represented in differential diagnosis of fever of unknown origin (FUO). The mainstay for the proper diagnosis of FUO took right path for the correct investigations. Globally, Toxoplasma gondii infection persists lifelong within the affected host organs in the dormant bradyzoites form. Once the host immunity decreases, it can be converted back to the activate tachyzoite form that attach the host cells. The aim of our study is to estimate the frequency of toxoplasmosis in patients with fever of unknown origin, concerning the etiology. A cross-sectional study was done from November 2017 to May 2018, including 140 patients chosen with FUO (100 males \&40 females), recruited from Port Said Fever Hospital/ Egypt. Their ages ranged between 16 and 70 years old. Patients were subjected to comprehensive history taking, laboratory investigations, clinical and radiologic examination. Detection of antiToxoplasma IgM\&IgG antibodies was done by the Electrochemiluminescence immunoassay. Patients had fever with known origin proved by investigations, were excluded from the study. The results showed that $7.1 \%$ of the FUO cases were serologically positive for Toxoplasma IgG. Of them, $80 \%$ were females and $20 \%$ were males. About $70 \%$ of Toxopl-asma-IgG positive cases were represented with fever for 3 weeks, and 30\% were represented with fever for more than 3 weeks. The $70 \%$ of the target group had cervical lymphadenopathy and all of them had hepatosplenomegaly. Moreover, all cases were eating fast food.
\end{abstract}

Key words: Patients, Fever of unknown origin Toxoplasmosis, Lymphadenopathy

\section{Introduction}

When fever is continuously persistent for three weeks and evading any diagnosis, it is termed as fever of unknown origin. After many years of the unique description of FUO, it remains a serious challenge for clinicians (Mir et al, 2014). Designing the correct strategy for FUO diagnosis was tricky due to altering field that obliges a frequent updating consistent with the variation of its causes and reasons (Vanderschueren et al, 2003). In spite of the progress in diagnostic facilities, it was a complex question about, which are conflicting opinions (Knockaert et $a l, 2003)$. The FUO causes were demarcated as infections, tumors, non-infectious inflammatory diseases and miscellaneous. In developing countries, FUO cause was infectious but in developed countries the commonest were non-infectious inflammation (Natio et al, 2019). Apart from the initial tests contrast computed tomography or magnetic resonance imaging were used (Gafter-Gvili et al, 2014). More invasive examinations including, lumbar puncture, pleural, pericardial or ascitic fluid analysis, lymph node or bone marrow aspiration, and liver biopsy may be done, if indicated by the examination, lab or imaging test.

Toxoplasma gondii that causes toxoplasmosis is a worldwide disease (Rouatbi et al, 2019). Man is infected either congenitally or acquired. Congenital transmission occurs during acute toxoplasmosis in a seronegative mother when tachyzoites present in blood might cross the placenta and infect the fetus (Jones et al, 2009). The prevalence varies geographically according to primary Toxoplasma infection in women risk of childbearing age (McAuley, 2008). Infection is mainly acquired by ingestion of food or water that is contaminated with oocysts shed by 
cats or by eating undercooked or raw meat containing tissue cysts. Infection acquired during pregnancy may cause severe damage to fetus (Montoya and Liesenfeld, 2004). Also, acquired nosocomial toxoplasmosis infection was reported (Saleh et al, 2016) with blood transfusion and needle-stick injury (Abdel-Motagaly et al, 2017). In Egypt, prevalence of $T$. gondii-antibodies was reported among chickens and pigeons (Rifaat et al, 1969), camels (Hilali et al, 1998), rabbits (Harfoush and Tahoon, 2010), and different edible animals (Fereiga et al, 2016), as well as in pet \& stray animals (Khalid et al, 1982), and domestic and wild rodents (Morsy et al, 1987). Besides, T. gondii antibodies were reported in Egyptian children with fever (Wishahy et al, 1971a) in Egyptian blood donors (Elsheikha et al, 2009). Only 10-20\% of toxoplasmosis cases in adults and children are symptomatic, but acute was often asymptomatic in healthy adults (Dubey and Jones, 2008). Symptoms may manifest as influenza-like: swollen lymph nodes, headaches, fever, and fatigue, or muscle aches and pains that last for a month or more. People with weakened immune systems were likely to experience headache, confusion, poor coordination, seizures; lung problems resemble tuberculosis or Pneumocystis pneumonia (a common opportunistic infection in AIDS people), or blurred vision caused by severe retina inflammation (Weiss and Dubey, 2009).

A prospective study on FUO was carried out in the Department of Internal Medicine, SKIMS, Kashmir; India and declared that infections produced by protozoa represented about $7.5 \%$ of cases (Mir et al, 2014). The seroprevalence of toxoplasmosis is widely varied from $6.1 \%$ to $74.5 \%$ along different regions of the world (Sakikawa et al, 2012). Lymphadenitis is the frequent symptom, any node may be infected, and the deep cervical nodes are mainly involved. The infected node is usually tender. Lymphadenopathy may be accompanied by fever, malaise, fatigue, muscle pains, rash, sore throat, and headache (Dubey, 1996). The fever of unknown origin and the weakness in the upper legs were reported among presented symptoms of acute toxoplasmosis in immune-competent individuals (Mentink et al, 2017).

\section{Patients and Methodology}

The present research was a cross-sectional study between November 2017 and May 2018, on patients attending Port-Said Fever Hospital $\mathrm{MOH}$, under the supervision of the Tropical Medicine Department, Faculty of Medicine, Zagazig University, Egypt. The patients were 140 chosen with FUO (100 males \&40 females), with ages ranged between $16 \& 70$ years.

Inclusion and exclusion criteria: Cases were chosen suffered from pro-longed fever for three weeks or more with unknown origin and with or without lymph node enlargement, or splenomegaly. But, patients with a diagnosed fever were excluded.

All patients were subjected to: 1- Personal and medical history: name, age, sex, eating habits: fast foods, sausage or luncheon (raw and under cocked meat kind), dealing with animals, as well as previous hospital admission with FUO (continuous, or intermittent, or relapsing), antibiotics treatment, history of pregnancy, chemotherapy or steroids treatment, diabetes mellitus and hypertension. 2Clinical examination: checking vital signs, chest and abdominal examination, eye examination for jaundice, any abnormal body swelling or lymph node. 3- Radiologic Investigations: Chest X-ray, abdominal and pelvic ultrasonography (US) and CT imaging were done. 4- Laboratory investigation: aStool and urine analysis were performed, bHematological assessment including complete blood count (CBC) using automated cell counters (CELL-DYN 1700), erythrocyte sedimentation rate (ESR) and blood film examination were done., c- Biochemical assessment was done including liver function tests (ALT, AST, serum albumin, serum bilirubin), renal function tests by HITACHI 912 automatic analyzer (Roche Diagnostics GmbH. Sandhofer Str. Mannheim, D-68298 Germany) and random blood sugar as well. 
Serological assessment: 1- Sera HCV antibody using an anti-HCV enzyme immunoassay kit for qualitative determination of antibodies to hepatitis $\mathrm{C}$ virus (anti-HCV) in human serum or plasma samples using ELISA kits (Diasorin S.p.A. 13040 Saluggi, Vercelli, Italy). Same kit was used for qualitative determination of hepatitis B surface antigen (HBs-Ag) in human sera. Antibody (HAV) IgM was done by radioimmunoassay.

2- Thyroid function tests, anti-nuclear antibody (ANA) and anti-double-strand DNA (anti-ds-DNA) for systemic lupus erythematosus (SLE) were done using Electrochemiluminescence practicing Cobas e411 (Roche Diagnostic GmbH, SandhoferStrasse 116, D-68305 Marnheim, Germany).

3- C-reactive protein (CRP) and lactate dehydrogenase (LDH) levels were measured.

4- Widal test, Brucella agglutination titer test, and TB skin test were carried out.

5- Anti-Toxoplasma IgM \& IgG antibodies were assessed by electrochemiluminescence immunoassay using Cobas e411 (Roche Diagnostic GmbH, Sandhofer/Strasse 116, D-68305 Marnheim, Germany) according to manufacturer's instructions. Both Cobas ${ }^{\circledR}$ Toxo-IgG \& IgM assays contained a soluble form of recombinant native-like folded; immunodominant surface antigen1 protein (SAG1 or p30) showed an elevated reactivity. Application of a voltage to electrodes induced electrochem-iluminescence reaction $\&$ resulting light emission was measured by photomultiplier (Marquette and Blum 2008).

Ethical Considerations: The study was carried out in compliance with the Helsinki De claration. An informed consent was taken from each patient and the study aim was explained to patients. No harm was caused to patients as blood samples were routinely collected from patients. The study approval was obtained from the Institutional Review Board (IRB) Unit, Faculty of Medicine, Zagazig University, Egypt (no. 4056).

Statistical analysis: Data were collected, tabulated and analyzed using SPSS 22.0 for windows (SPSS Inc., Chicago, IL, USA). Continuous data were conveyed as $\mathrm{M} \pm \mathrm{SD}$ and the median (range). Categorized data were expressed as a number (percentage).

\section{Results}

The results showed that Toxoplasma IgG level ranged from 0.09 to 1527 with a mean value of 51.71 and about $7.1 \%$ of Toxoplas$m a$ infection patients (Tab. 1). Toxoplas$m a \operatorname{IgM}$ among ranged from 0.1 to 0.4 with a mean value of 0.08 (col) (Tab. 2), with significance $(\mathrm{P}<0.05)$ positive correlation between IgG \& IgM levels (Tab. 3). Toxopla$s m a-\operatorname{IgG} \&$ IgM levels in infected cases and control showed high significance increase in IgG \& IgM levels among Toxoplasma patients compared to control (Tab. 4).

The demographic data, a highly significance $(\mathrm{P}<0.01)$ increase was in Toxoplasma infection females but without significance differences in age between patients and control (Tab. 5).

Handling the history, clinical examination and presentation, the target groups of toxoplasmosis were free from any chronic diseases, while the rest of cases showed 2 cases with hypertension and type 1 diabetes, 2 cases with renal disease and 2 cases had abortion. The clinical examination showed about $70 \%$ of the target group had cervical lymphadenopathy, whereas $50 \%$ of the other cases with lymphadenopathy. Also, $70 \%$ of patients with fever for 3 weeks, but $30 \%$ of them had fever for more than 3 weeks, without significance differences (Tab. 6). All toxoplasmosis cases ate fast food, $16.7 \%$ ate beef and $11.5 \%$ uncooked meat (Fig. 1).

Lab examinations showed that toxoplasmosis patients had normal liver and kidney function tests, but CBC showed abnormal eosinophilia. Imaging findings particularly ultrasonography proved hepatosplenomegaly in all toxoplasmosis cases (Tab. 7).

The details were given in tables $(1,2,3,4$, $5,6 \& 7$ ) and figure (1). 
Table 1: Toxoplasma prevalence and level of IgG among groups

\begin{tabular}{|c|c|}
\hline Variable & $(n=140)$ \\
\hline $\begin{array}{l}\text { IgG: }(\mathrm{IU} / \mathrm{ml}) \\
\text { Median } \\
\text { Range }\end{array}$ & $\begin{array}{c}51.71 \pm 233.56 \\
0.55 \\
0.09-1527\end{array}$ \\
\hline $\begin{array}{c}\text { Toxoplasma: }(\mathrm{By} \operatorname{IgG}) \\
\text {-ve } \mathrm{N}(\%) \\
\text { +ve } \mathrm{N}(\%)\end{array}$ & $\begin{array}{c}130(92.9 \%) \\
10(7.1 \%)\end{array}$ \\
\hline
\end{tabular}

IgG normal value: $<1 \mathrm{IU} / \mathrm{ml}$ non-reactive, $1-<3 \mathrm{IU} / \mathrm{ml}$ intermediate, $\geq 3 \mathrm{IU} / \mathrm{ml}$ reactive

Table 2: Toxoplasma IgM level among groups:

\begin{tabular}{|l|c|}
\hline \multicolumn{1}{|c|}{ IgM: $(\mathrm{Col})$} & $(\mathrm{n}=140)$ \\
\hline Mean $\pm \mathrm{SD}$ & $0.08 \pm 0.07$ \\
Median & 0.06 \\
Range & $0.1-0.4$ \\
\hline
\end{tabular}

IgM normal value: $<0.08 \mathrm{Col}$ non-reactive, $0.8-<1 \mathrm{Col}$ intermediate, $\geq 1 \mathrm{Col}$ reactive

Table 3: Toxoplasma IgG \& IgM levels among groups:

\begin{tabular}{|c|c|c|}
\hline Variable & $\operatorname{IgM}(\mathrm{col})(\mathrm{n}=140)$ \\
\cline { 2 - 3 } & $\mathrm{r}$ & $\mathrm{P}$ \\
\hline IgG: $(\mathrm{IU} / \mathrm{ml})$ & 0.34 & $0.04^{*}$ \\
\hline
\end{tabular}

Table 4: Comparison between cases with or without Toxoplasma with reference to IgG\&IgM levels:

\begin{tabular}{|c|c|c|c|c|}
\hline Variable & No Toxoplasma $(\mathrm{n}=130)$ & Toxoplasma $(\mathrm{n}=10)$ & MW & $\mathrm{P}$ \\
\hline IgM: $(\mathrm{Col})$ & $0.07 \pm 0.07$ & $0.14 \pm 0.07$ & & \\
Median & 0.06 & 0.10 & 3.55 & $<0.001$ \\
Range & $0.01-0.4$ & $0.09-0.27$ & & $* *$ \\
\hline IgG: $(\mathrm{IU} / \mathrm{ml})$ & $0.50 \pm 0.27$ & $717.46 \pm 558.73$ & & \\
Median & 0.49 & 380.2 & 5.26 & $<0.001$ \\
Range & $0.09-0.99$ & $357.6-1572$ & & $* *$ \\
\hline
\end{tabular}

**Highly significant $(\mathrm{P}<0.01)$, IgM normal value: $<0.08$ Col non-reactive, $0.8-<1$ Col intermediate, $\geq 1$

Col reactive $\mathrm{IgG}$ normal value: $<1 \mathrm{IU} / \mathrm{ml}$ non-reactive, $1-<3 \mathrm{IU} / \mathrm{ml}$ intermediate, $\geq 3 \mathrm{IU} / \mathrm{ml}$ reactive

Table 5: Comparison between cases with or without Toxoplasma with reference to demographic data:

\begin{tabular}{|l|c|c|c|c|}
\hline \multicolumn{1}{|c|}{ Variable } & No Toxoplasma $(\mathrm{n}=130)$ & Toxoplasma $(\mathrm{n}=10)$ & MW & $\mathrm{P}$ \\
\hline Age : (years) & $23.36 \pm 13.52$ & $22.6 \pm 5.36$ & 0.21 & 0.84 \\
Median & 24.5 & 21 & & NS \\
Range & 1663 & $16-58$ & & \\
\hline Female & $40(30.8 \%)$ & $8(805)$ & & \\
Male & $90(69.2 \%)$ & $2(205)$ & $\left(\chi^{2}\right) 9.99$ & $0.002^{* *}$ \\
\hline
\end{tabular}

NS: Non significant $(\mathrm{P}>0.05) \quad * *$ : Highly significant $(\mathrm{P}<0.01)$

Table 6: Comparison between cases with or without Toxoplasma regarding history, examination and presentation:

\begin{tabular}{|c|c|c|c|c|c|c|}
\hline \multirow[t]{2}{*}{ Variable } & \multicolumn{2}{|c|}{ No Toxoplasma $(\mathrm{n}=130)$} & \multicolumn{2}{|c|}{ Toxoplasma $(\mathrm{n}=10)$} & \multirow[b]{2}{*}{$\chi^{2}$} & \multirow[b]{2}{*}{$\mathrm{P}$} \\
\hline & No & $\%$ & No & $\%$ & & \\
\hline Past history: Toxoplasma -ve & 124 & 95.4 & 10 & 100 & 0.32 & 0.85 \\
\hline Toxoplasma $+v e$ & 6 & 4.6 & 0 & 0 & & NS \\
\hline $\mathrm{HPT}+\mathrm{DM}$ & 2 & 1.5 & & & & \\
\hline Renal disease & 2 & 1.5 & & & & \\
\hline Abortion & 2 & 1.5 & & & & \\
\hline Examination: Free & 65 & 50 & 3 & 30 & 1.49 & 0.22 \\
\hline Cervical lymphadenopathy & 65 & 50 & 7 & 70 & & NS \\
\hline Presentation: Fever for 3 weeks & 62 & 47.7 & 7 & 70 & 1.85 & 0.17 \\
\hline Fever more than 3 weeks & 68 & 52.3 & 3 & 30 & & NS \\
\hline
\end{tabular}

$\chi^{2}$ :Chi square test NS: Non significant $(\mathrm{P}>0.05)$

Table 7: Imaging findings of studied cross-section $(\mathrm{N}=141)$.

\begin{tabular}{|l|c|c|}
\hline Imaging findings & No. & $\%$ \\
\hline Plain X-ray chest Normal & 140 & $100 \%$ \\
\hline Plain X-ray chest Abnormal & 0 & $0 \%$ \\
\hline Ultrasonography Enlarged fatty liver & 10 & $7.1 \%$ \\
\hline Ultrasonography Splenomegaly & 46 & $32.8 \%$ \\
\hline
\end{tabular}

\section{Discussion}

Fever of unknown origin is a mystifying medical risky problem. It is announced as a fever more than $38.30^{\circ} \mathrm{C}$ for at least three weeks, lacking diagnosis even with appropriate investigations (Bleeker-Rovers et al, 
2009). Long ago many diseases caused FUO counting infections, neoplasms, connective tissue diseases, miscellaneous disorders, and undiagnosed illnesses (Mackowiak and Durack, 2010).

Human toxoplasmosis is a global zoonotic infectious disease. Toxoplasma infection may alter the host cell function even in the absence of invasion (Koshyet al, 2012). Human toxoplasmosis may be clinically presented with atypical features such as FUO (Alavi and Alavi, 2016). The current study aimed to detect the frequency of toxoplasmosis in the cases represented by fever of unknown origin.

The present study included 140 patients with fever of unknown origin, with a range of 16-70 years old. Middle aged patients were the most represented among FUO cases. By using immunochemiluminescence assay, the results showed that $7.1 \%$ of them were serologically positive for Toxoplasma IgG. Comparable with the results that estimated 1.1 million USA inhabitants were $T$. gondii infected annually, and approximately $10.4 \%$ of the population gave seroprevalence linked to past exposure (Jones et al, 2018).

The present results showed an increased infection percentage (80\%) among adult females. Also, about $52.2 \%$ of pregnant women in Menoufia Governorate/Egypt were seropositive for the anti-Toxoplasma IgG antibodies (Nassef et al, 2014). But, the seroprevalence of human toxoplasmosis reached up to $54 \%$ in diabetic patients compared with control normal (24\%) in randomly selected from Al Hussein University Hospitals /Egypt (Hemida et al, 2018). Also, a sample of young Iranian females presented for premarital investigations, $T$. gondii sero-positivity was $15 \%$ (13\% for IgG \& $2 \%$ for $\operatorname{IgM})$ by using ELISA (Alavi and Alavi, 2016). This variation might be due to the fact that the present study dealt with males and females. Besides, females are always in contact with sources of infection e.g. raw meat, home duty, marketing, farming (rural areas) as well as dealing with pet or domestic animals In the present study, cases that ate fast food (beef) showed $16.7 \%$ positive Toxoplasma IgG cases whereas, those ate them were ate under-cooked meat were $11.5 \%$. This agreed with Abd El-Razik et al. (2014) who found that shawarma, menaced meat, luncheon, superficial pastrami, and boiled chickens were PCR positive but rusted meat and brain materials gave higher $T$. gondii ELISA antibodies. A case-control study indicated that the consumption of mutton/lamb meat was a highly significant risk factor for contracting $T$. gondiii nfection in pregnant women (Fusco et al, 2007).

In the present study, FUO cases were admitted to the hospital, $50 \%$ had cervical lymphadenopathy, 70\% had fever for 3 weeks, and $30 \%$ had fever for more than 3 weeks. Wishahy et al. (1971b) reported Egyptian children with mediastinal lymphadenopathy. Sathapatayavongs et al. (1983) reported that cervical lymph nodes were the commonest picture of toxoplasmosis, followed by axillary lymph nodes. The present result agreed with Nardone et al. (2006) who reported that about $80-90 \%$ of asymptomatic Toxoplasma patients had painless cervical lymphadenopathy. Besides, Abdullah and Hamza (2017) reported a case of submandibular and supraclavicular nodes with high titers of Toxoplasma IgG \& IgM antibodies.,

In the present study, abdominal ultrasonography showed hepatosplenomegaly for cases with toxoplasmosis. Bossi and Bricaire (2004) found that some patients developed severe symptoms, including generalized lymphadenopathy, and hepato-splenomegaly. Atilla et al. (2015) foundd that toxoplasmosis must be considered in the patients with hepatitis or hepatomegaly.

\section{Conclusion}

Diagnosis of FUO must be evaluated in different communities, for underlining the main etiology among different them. This study reported a significant number of serologically positive cases $(7.1 \%)$ for Toxoplasma-IgG. Adult males were the most rep- 
resented among FUO cases, toxoplasmosis is common in females. This can clarify the importance of counting Toxoplasma infection within differential diagnosis of FUO, especially those with cervical lymphadenopathy. More attention is needed to fast food as a risk factor for $T$. gondii infection. The imminent research will be the genotyping of Toxoplasma parasite infecting the pregnant and immunosuppressed cases for demonstration of its genetic diversity.

\section{References}

Abd El-Razik, KA, El-Fadaly, HA, Barakat, AMA, Abu-Elnaga, ASM, 2014: Zoonotic hazards $T$. gondii viable cysts in ready to eat Egyptian meat-meals. World J. Med. Sci. 11, 4:510-7. Abdel-Motagaly, AME, Ibrahim, AMA, Morsy, TA, 2017: An intervention program on blood protozoa acquired by needle stick injury and infection control. J. Egypt. Soc. Parasitol. 47, 2:309-22

Abdullah, M, Hamza, H, 2017: Toxoplasmosis and lymphoma: The mimickers. Indian J. Med. Paediatr. Oncol. 38, 2:248-50.

Alavi, SM, Alavi, L, 2016: Toxoplasmosis in Iran: A guide for general physicians working in the Iranian health network setting: A systematic review. Caspian J. Intern. Med. 7, 4:233-41.

ans, D, 2003: Fever of unknown origin in adults: 40 years on. J. Intern. Med. 253:263-75.

Atilla, A, Aydi, S, Demirdoven, A, Kilic, S, 2015: Severe Toxoplasmic Hepatitis in an Immunocompetent Patient. Jpn. J. Infect. Dis 68: 407-9.

Bleeker-Rovers, CP, van der, Meer, JW, Oyen, WJ, 2009: Fever of unknown origin. Semin. Nucl. Med. 39, 2:81-7.

Bossi, P, Bricaire F, 2004: Severe acute disseminated toxoplasmosis. Lancet 364:579.

Dubey, JP, 1996: Toxoplasma gondii. In: Medical Microbiology ( $4^{\text {th }}$ ed). Galveston (TX): University of Texas Medical Branch at Galveston. ISBN-10: 0-9631172-1-1.

Dubey, JP, Jones, JL, 2008: Toxoplasma gondii infection in humans and animals in the United States. Inter. J. Parasitol. 38, 11:1257-78.

Elsheikha, HM, El-Motayam, MH, Abouel-Nour, F, Morsy, AT, 2009: Oxidative stress and immune-suppression in Toxoplasma gondii positive blood donors: implications for safe blood transfusion. J. Egypt. Soc. Parasitol. 39, 2:421-8
Fereiga, RM, Mahmoud, HY, Mohamed, SG, AbouLaila, MR, Abdel-Wahab, A, et al, 2016: Seroprevalence and epidemiology of Toxoplasma gondii in farm animals in different regions of Egypt. Vet. Parasitol. Reg. Stud. Rprts. 3-4:1-6.

Fusco, G, Rinaldi, L, Guarino, A, Proroga, Y, Pesce, A, et al, 2007: Toxoplasma gondii in sheep from the Campania region (Italy). Vet. Parasit. 149:271-4.

Gafter-Gvili, A, Raibma, S, Grossman, A, Avni, T, Paul, M, et al, 2014: FDG-PET/CT for the diagnosis of patients with fever of unknown origin. QJM. 108, 4: 267-9.

Harfoush, M, Tahoon, AN, 2010: Seroprevalence of Toxoplasma gon-dii antibodies in domestic ducks, free-range chickens, turkeys and rabbits in Kafr El-Sheikh Governorate Egypt. J. Egypt. Soc. Parasitol. 40, 2: 295-302.

Hemida, MH, Shahat, SA, Bayoumy, AM, Mohamed, KA, Hassan, SM, 2018: Toxoplasmosis prevalence in Egyptian diabetic patients. Al-Azhar Assiut Med. J. 16, 2:113-6.

Hilali, M, Romand, S, Thulliez, P, Kwok, OC, Dubey, JP, 1998: Prevalenceof Neospora caninum andToxoplasma gondii antibodies in serum from camels from Egypt. Vet. Parasitol.75, 2/3: 269-71.

Jones, JL, Dargelas, V, et al, 2009: Risk factors for Toxoplasma gondii infection in the United States. Clin. Infect. Dis. 49, 6:878-84.

Jones, JL, Kruszon-Moran, D, Elder, S, Rivera, HN, Press, C, et al, 2018: Toxoplasma gondii infection in the United States 2011-2014. Am. J. Trop. Med. Hyg. 98: 551-557.

Khalid, MLM, Morsy, TA, Sadek, MSM, Salama, MI, 1982: The presence of antibodies against toxoplasmosis, leishmaniasis and amoebiasis in stray dogs in Cairo, Egypt. J. Egypt. Soc. Parasitol. 12, 2:341-7.

Knockaert, DC, Vanderschueren, S, BlockmKoshy, AA, Dietrich, HK, Christian, DA, Melehani, JH, Shastri, AJ, et al, 2012: Toxoplas$m a$ coopts host cells it does not invade. PloS Pathog. 8, 7:e1002825.

Mackowiak, PA, Durack, DT, 2010: Fever of unknown origin. In: Mandell GL, Bennett JE, Dolin R. Mandell, Douglas, and Bennett's Principles and Practice of Infectious Diseases ( $7^{\text {th }}$ ed). Philadelphia: Elsevier Churchill Livingstone.

Marquette, CA, Blum, LJ, 2008: Electrochemiluminescentbiosensing. Anal. Bioanal. Chem. 390:155-68.

McAuley, JB, 2008: Toxoplasmosis in children. 
Pediatr, Infect. Dis J. 27:161-4.

Mentink, JF, Rijn, M, Dees, A, 2017: A fever of unknown origin as a presenting symptom in toxoplasmosis: Back to earth. Int. J. Case Rep. Images 8, 1:73-6.

Mir, T, Nabil Dhobi, G, NabiKoul, A, Saleh, T, 2014: Clinical profile of classic fever of unknown origin. Caspian J Intern. Med. 5, 1:35-9.

Montoya, JG, Liesenfeld, O, 2004: Toxoplasmosis. Lancet 363, 9425:1965-76.

Morsy, TA, Shoukry, A, Abu-Hashish, TA, El Kady, GA, 1987: Toxoplasma antibodies in commensal rodents in El Arish City, Egypt. J. Egypt. Soc. Parasitol. 17, 2:799-801.

Nardone, H, Kirse, J, Roberson, DW, 2006: Infectious and inflammatory disorders of the neck. In: Ralph F. Wetmore, Harlan R. Muntz, McGill TJ (eds.) Pediatric Otolaryngology Principles and Practice Pathways. Thieme Medical.

Nassef, NE, Abd-El-Ghaffar, MM, El-Nahas, NS, Hassan, MA, Shams-El-Din, SA, et al, 2014: Seroprevalence and genotyping of Toxoplasma gondii in Menoufia Governorate. Menoufia Med. J. 28: 617-26.

Natio, T, Tanei, M, Ikeda, N, et al, 2019: Key diagnostic characteristics of fever of unknown origin in Japanese patients: a prospective multicentre study. BMJ Open 19, 9:11-7.

Rifaat, MA, Morsy, TA, Sadek, M.S.M, 1969: Toxoplasmosis in chickens and pigeons in UAR. (Preliminary report). J. Trop. Med. Hyg. 72:1934.

Rouatbi, M, Amairia, S, Amdouni, Y, Boussa- adoun, MA, Ayadi, O, 2019: Toxoplasma gondii infection and toxoplasmosis in North Africa: a review. Parasite 2019;2 6:6. doi: 10.1051.

Sakikawa, M, Noda, S, Hanaoka, M, et al, 2012: Anti-Toxoplasma antibody prevalence, primary infection rate, and risk factors in a study of toxoplasmosis in 4466 pregnant women in Japan. Clin. Vacc. Immunol. 19:365-7.

Saleh, AMA, Al-Agroudi, MA, Morsy, TA, 2016: Occupational, noso-comial or hospital acquired toxoplasmosis. J. Egypt. Soc. Parasitol. 46, 3:407-18.

Sathapatayavongs, B, Batteiger, BE, Wheat, J, Slama, TG, Wass, JL, 1983: Clinical and laboratory features of disseminated histoplasmosis during two large urban outbreaks. Medicine 62: 263-70.

Vanderschueren, S, Knockaert, D, Adriaenssens, T, et al., 2003: From prolonged febrile illness to fever of unknown origin: the challenge continues. Arch. Intern. Med. 163:1033-41.

Weiss, LM, Dubey, JP, 2009: Toxoplasmosis: A history of clinical observations. Int. J. Parasitol. 39, 8:895-901.

Wishahy, AO, Rifaat, MA, Morsy, TA, EI Naggar, BA, 1971a: Three cases of toxoplasmosis manifesting with fever. Gaz. Egypt. Paediatr. Assoc. 20, 1:103-6.

Wishahy, AO, Rifaat, MA, Morsy, TA, EI Naggar, BA, 1971b: Toxoplasmosis in an Egyptian child with mediastinal lymphadenopathy. J. Trop. Med. Hyg., V. 74, Pp.: 82, London.

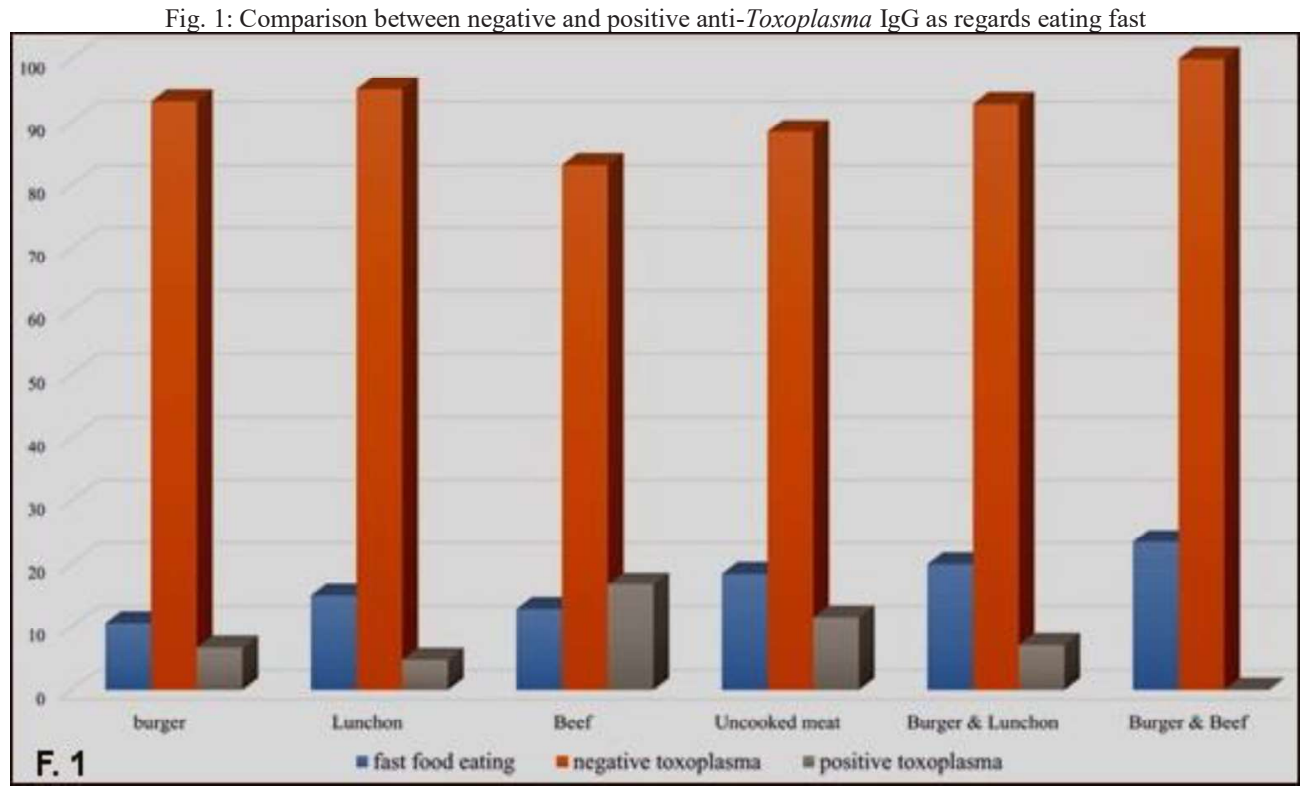

